\title{
Hindering Factors towards Male Participation in the PMCTCT HIV/AIDS Prevention Program: A Case of Lesotho
}

\author{
Thandiwe Marethabile Letsie ${ }^{1}$ \& Mafusi Jemina Mokone ${ }^{2}$ \\ ${ }^{1}$ Bloemfontein Free State, South Africa \\ ${ }^{2}$ Elizabeth Glazer Paediatric Foundation Maseru Lesotho, South Africa \\ Correspondence: Thandiwe Marethabile Letsie, Bloemfontein Free State, South Africa. Tel: 27-833-793-156.
}

Received: August 7, 2019 Accepted: January 10, 2021 Online Published: February 10, 2021

doi:10.5539/gjhs.v13n3p101

URL: https://doi.org/10.5539/gjhs.v13n3p101

\begin{abstract}
HIV/AIDS remains a concern in many countries globally. Different governments have put in place preventative measures aimed at ensuring healthy nations. PMCTC HIV/AIDS as one antenatal preventive program, is a safe motherhood initiative offering comprehensive reproductive services that are more inclusive. A qualitative descriptive and explorative achieved through in-depth one-to-one interviews done established factors hindering the males in Lesotho from participating in the prevention of mother to child human immunodeficiency virus transmission (PMTCT). Tesch approach was used to analyse qualitative data and the following four themes emerged; Socio-cultural practices, lack of time by most men who are working, inadequate information to the male partners regarding reproductive related issues and educative strategies. The concerns raised by Basotho men are enlightening and call for management of health care services to align research with transformative legislation influencing reproductive health care policy. Measures aimed at improving internal processes within PMCTC umbrella address administrative issues compromising care. Therefore, constant capacity development on nursing teams to buy-into offering inclusive client centred PMCTC services is a sensible approach.
\end{abstract}

Keywords: factors, hindering, participation, males \& PMTCT HIV/AIDS transmission

\section{Introduction and Background}

The prevalence of HIV/AIDS remains the global concern calling for continued discourse on meaningful measures to curtail the pandemic where about 6000 people continue to be infected daily (Kharsany \& Karim, 2016). In 2017, about 36.9 million were living with HI virus. About 21.7 million people accessed the antiretroviral therapy. One million eight hundred thousand (1.8 million) people were HIV infected in 2017 and approximately 940000 people died from AIDS-related illness (UNAIDS, global HIV and AIDS statistics-2018 fact sheet, 2018). This paper, seeks to explore factors preventing male partners of HIV positive women in Lesotho from participating in the Prevention of Mother to Child (PMTCT) HIV/AIDS prevention program.

The world Health Organization promotes a more comprehensive family-centered approach through PMTCT HIV/AIDS prevention platforms enhancing accessibility to quality antenatal care offering a range of comprehensive services like; HIV screening, use of anti-retroviral treatment (ART) for family, safe birthing practices, appropriate infant feeding techniques and other post-natal related services (Avert, Global information and education on HIV/AIDS, 2016). The PMTCT HIV/AIDS prevention platform promotes counselling and HIV testing at 14 weeks' pregnancy. The mothers with Cluster of Differentiation Antigen4 (CD4) above 350 qualify for anti-retroviral (ARV) prophylaxis. The different screening tests performed through PMCTC HIV/AIDS prevention initiative, offers health care providers the opportunity to create a rapport with the client and create a medical history baseline. The therapeutic encounter of the client with professional team facilitates excellent health outcomes. However, participation of males in HIV/AIDS preventative remains a key challenge compromising envisaged health care outcomes (Avert, Global information and education on HIV/AIDS, 2016).

The PMCTC HIV/AIDS prevention initiative aims at preventing new HIV infection among women of childbearing age group, preventing unintended pregnancy among women living with HIV and prevention of vertical transmission through supporting families. Full integration of males in PMCTC HIV/AIDS prevention programs still remains a challenge in different parts of world due to reasons like; related stigma, migrant labor, possible discrimination by families and communities, partner irreconcilable conflicts resulting domestic violence and 
possible abandonment by wife (Avert, Global information and education on HIV/AIDS, 2018).

The problem of HIV/AIDS is more eminent in developing countries due to a number of socio-economic, challenges still existing in developing continents like Africa, Latin America \& Asia. For instance, Sub-Saharan African countries carry disproportionate burden of HI virus, accounting for more than (70\%) of the global burden of infection. One million five hundred thousand (1.5million) deaths occurred globally in 2013 and (74\%) were from sub-Saharan African countries (Kharsany \& Karim, 2016). The HIV prevalence among children ages 0-14 was about (2.1\%) in 2016. Adolescent girls and young women between ages 15-24 years are eight times at the risks of being HIV infected than their male peers (Kharsany \& Karim, 2016). A more inclusive family centered approach recognizes the crucial position of males in reproductive related issues (Avert, Global information and education on HIV/AIDS, 2018).

The HIV/AIDS pandemic remains a concern in middle economies like South Africa. The South African population estimated at 56.52 million in 2017 and the total number of females is about 28.9 million constituting about (51\%) of the population. The HIV prevalence among adults within the age bracket of 15-45 was about (18\%) (South Africa, Department of Statistics, 2017). The overall HIV prevalence rate of HIV infection within the South Africa population is 7.06 million people (12.6\%), and the life expectancy of males is about 61 and that of females is 67 . The infant mortality rate in 2017, was about 32.8 per 1000 live births (South Africa, Department of Statistics, 2017). Challenges relating to full integration of males within the PMCTC HIV/AIDS prevention program in South Africa is associated with issues like; unemployment, tight work schedule for the males who sometimes travel long distances to work and labor migration to more affluent nations and so on (South Africa, Department of Statistics, 2017).

The predicament of high HIV prevalence rate in Lesotho poses a challenge to the country with the population of 2.2 million people and it has the second highest prevalence rate in the world (Avert, Global information and education on HIV/AIDS, 2017). The following high-risk groups bear the significant brunt of HIV infection; sex workers $(79.1 \%)$, factory workers $(42 \%)$, homosexual men $(32 \%)$, prison inmates $(31 \%)$, pregnant women $(25 \% .9 \%)$, young women $(10.2 \%)$, young men $(5.9 \%)$ and the general population (23\%) (Avert Global information and education on HIV/AIDS, 2017). The reflected figures still raise a concern that despite existing preventative strategies aimed at curbing the pandemic, different community members within the prime employment age bracket, still bear the HIV/AIDS brunt (Avert, Global information and education on HIV/AIDS, 2017).

The inception of PMCTC HIV/AIDS prevention initiative is having a significant impact in reducing new HIV infections from 4,400 in 2009 to 1,300 in 2015. Notable progress achieved through decreasing the number of deaths among HIV positive children under the age of five, from 86 in 2004 to 260 in 2014. Males are significant role players in controlling the spread of HIV/AIDS. Therefore, measures aimed at fully incorporating them within the PMCTC basket is quite sensible (Avert, Global information and education on HIV/AIDS, 2018).

Lesotho as a lower to middle-income economy where fifty-seven percent (57\%) of the population still lives below the poverty line, the HIV scourge has significantly contributed to the low life expectancy of 52, for men and 55 for women (Avert, Global information and education on HIV/AIDS, 2017). Twenty-five percent (25\%) of the population is HIV positive. About 330000 lived with HIV in 2016 contrary to the recorded 21,000 cases in 2005. Commendable progress in the management of HIV/AIDS has resulted in dramatic coverage of testing and rolling of Anti Retro Viral (ARV) treatment. However, deterrents like; poverty, gender inequalities and HIV stigma and discrimination are outstanding. Therefore, constant engagement with relevant stakeholders to improve existing preventative approaches is necessary (Avert, Global information and education on HIV/AIDS in Lesotho 2017).

The HIV/AIDS epidemic in Lesotho is still a concern because of altered family life for many young people orphaned due to parents dying of AIDS related illnesses. In Lesotho, there are 73,000 AIDS orphans being compelled to care for younger siblings and grandparents after deaths of parents (Avert, Global information and education on HIV/AIDS in Lesotho 2017). Therefore, the inclusive nature of reproductive related programs like PMCTC HIV/AIDS prevention programs offering counselling services instill a sense of responsibility on the males who are leaders of families on the significance of participating in the preventative initiatives through encouraging safer sex (Avert, Global information and education on HIV/AIDS, in Lesotho, 2017).

About (72\%) of people living with HIV are aware of their status in Lesotho. The significant progress achieved through different mass media platforms is empowering communities on the dangers of HI virus. However, there are still outstanding barriers affecting preference of these PMCTC HIV/AIDS prevention programs by vulnerable people in communities. Such barriers include; the related HIV/AIDS stigma and associated violence. These are key deterrents to many communities (Avert, Global information and education on HIV/AIDS, in Lesotho, 2017). 
Women are equally significant role players in HIV/AIDS related conversations. Literature affirms that the plight of women influenced by an array of socio-economic and gender related factors as contributory to the increasing number of HIV/AIDS infection in women globally (Akinsola \& Mulaudzi, 2009). The common causes of HIV transmission in women include their biological make up, differing significantly from that of men. Women have a much larger surface area of skin and tissue in their genitalia, which creates much HIV exposure for them from their partner's secretions (semen) during sexual intercourse. Akarro, Deonisia, Sichona (2011) agree that more comprehensive and inclusive PMTCT HIV/AIDS Prevention programs are required to educate males on the need to protect their pregnant partners, and their unborn children.

The socio-economic and gender related setbacks in developing countries put women in a position which does not allow them to bargain for practice of safer sex (Joubert-Wallis \& Fourie, 2008). The result of women being in a compromising position due to lack of money compels them into being sex workers, or into having multiple concurrent partners to get financial incentives to survive (Joubert-Wallis \& Fourie, 2008). Another setback posing as risk to African women is lack of education. A significant proportion of girls in rural parts of Africa have less literacy level compared to boys who have better chances for job opportunities (Rountree, Pomeroy, \& Marsiglia, 2008). The lack of financial power, compromises the bargaining power of females for safer sex. Women that are more vulnerable tend coerced into unprotected sex are vulnerable towards contracting HIV infection (Rountree, et al., 2008).

In different African cultures, men are still the sole decision makers in different matters, including the sexual issues (Joubert-Wallis \& Fourie, 2008) \& WHO and UNAIDS report on antiretroviral drugs (2009). The polygamous culture being rife compromises health of families. This practice is a gross violation of female rights who are vulnerable for HIV infection by the husband usually having multiple wives. In Lesotho, the Christian denomination accounts for $(85 \%)$ population contrary to secular values gained in avenues like traditional initiation schools, which are still quite common in the rural areas especially. However, a serious concern is that cultural and Christian values seemingly have no significant influence on improving the moral fiber of the society (Joubert-Wallis \& Fourie, 2008).

The dawn of HIV and constant campaigning on the dangers of the disease is seeing the decline in polygamous practices within rural communities. The patriarchal nature of Basotho culture positions men as head of families compelling them to be more self-sustainable and even provide for the extended families. Subsistence farming including animal and crop farming becomes a common way of making a living for families residing in the high and lowlands regions of the country where employment opportunities are scarce. The rural women lack financial power due to limited job opportunities compounded by lack of education. This compromises their ability to negotiate for safer sex (Joubert-Wallis \& Fourie, 2008).

The financial pressure experienced by rural men in Lesotho compels them to look for better job opportunities in the lowlands. Diamond mining is gradually gaining momentum in the northern parts of Lesotho close to the Drakensberg range. Also quite a significant proportion of Basotho males are absorbed as migrant laborers in the South African mines making them more stable financially than the female partners. The separate lifestyles with families leads to promiscuous lifestyle and becomes quite difficult to integrate these men into the PMTCT HIV/AIDS prevention programs (Ehrhardt, Sawires, McGovern, Peacock, \& Weston, 2009). This setback frustrates the preventative benefits of PMCTC program (Ehrhardt et al., 2009).

\section{Methods}

\subsection{Study Design}

HIV/AIDS is a serious socio-economic concerns in many developing countries calling governments, civil society to collaborate through initiatives like PMCTC HIV/AIDs preventative programs. The exploratory, descriptive nature of in-depth face-to face interviews as a qualitative technique, becomes an architectural backbone detailing different modalities of the design, thereof minimising bias from a qualitative inquirer concerned with the plausibility of data. Therefore, critical aspects like; the technicalities of data collection, location of this study and so on enabled the researchers to establish hindering factors towards male participation in the PMCTC program (Polit \& Beck, 2012).

\subsection{Study Setting}

The in-depth one-to-one interviews conducted with the partners of HIV/AIDS positive women at the participants' home were insightful. The semi-urban village within the district concerned, was the setting of the study. The researcher made appointments with the participants, and some of them were not staying home, but coming home over weekends from different work assignments. Also, necessary arrangements made with the relevant authority 
prior entry formed part of gate keeping crucial to a qualitative inquirer. Each in-interview session took approximately 1-2hours.

\subsection{Population and Sampling}

All individuals or objects with common defining characteristics constitute the population in any study (Polit \& Beck, 2012). The partners of HIV/AIDS positive women attending antenatal care clinic at a district hospital during the period of the study constituted the population of this study. A non-probability sampling technique used in this study followed the qualitative principle that not every element within the population has the opportunity of selection in the sample (Burns \& Grove, 2009).

\subsection{Data Collection}

In-depth, one-to-one interviews technique was used to collect rich data from the participants. The participants were interviewed in their own homes and necessary privacy was offered. Ice breakers prior commencement of the interviews created the necessary rapport and improved interaction with the participants. The participants were warned that sessions would be recorded. Afterwards, a formal briefing session done prior each in-depth interview session clarified the purpose of the study. The participants agreeing to participate signed a voluntary consent form enabling them withdraw from participation if they felt so. A local language used during the in-depth interview sessions enabled the participants to express themselves with much ease. Each participant was asked this question; What are the factors hindering your participation in the PMCTC HIV/AIDS prevention program? Interviewing techniques like; reflection, paraphrasing and nodding improved interaction and improved the quality of data elicited. After each interview session, a debriefing enabled the participants to get more clarity on any issue outstanding (De Vos, Strydom, Fouche, \& Delport, 2008; Burns \& Grove, 2009). The principle of data saturation determined discontinuation of the interviews. The tape-recorded material kept safe was made accessible to those involved in the study.

\subsection{Data Analysis}

Data analysis in qualitative studies integrates reflective remarks in analysis process (Burns \& Grove, 2009). Eight Tesch's steps of qualitative data analysis used highlight the manner in which the researcher immerses themselves on the extensive raw data. The narratives/words synthesized, and create substantive themes and sub-categories (Brink, 2006; Creswell, 2009).

\subsection{Trustworthiness}

Trustworthiness is a qualitative technique assisting the constructivist to improve rigor of findings through specific procedures embarked upon. The confidence on the data by the inquirer is achieved through; credibility, dependability, confirmability and transferability (Polit \& Beck, 2012).

Credibility established through prolonged engagement offered enabled the interviewer to understand better the issue discussed. Member checking established through briefing and debriefing exercises. Integration of interviewing techniques by the interviewee included; reflection, paraphrasing and nodding at each interview. This offered clarity on any outstanding issues discussed. Transcription and analysis of data augmented with field notes including detailed documentation of non-verbal cues, and consideration of data saturation improved the quality of verbatim and its credibility (Netshiswinzhe \& Mulaudzi, 2015).

Dependability is the criteria used to assess the reliability of results in that if a similar study repeated in the same context with similar participants, the findings would be the same (Sibiya, Naidoo, \& Mjajubana, 2019). An audit trail of all the original taped records and notes done by the supervisor through extensive review of data improved dependability (Sibiya et al., 2019). Confirmability is the objectivity or neutrality of data achieved through congruency between several people through bracketing (Polit \& Beck, 2012). Verbatim was translated into English by an experienced language translator and the co-coder was engaged as part of the review of transcripts. A consensus of applicable themes and categories reached.

The plausibility that the qualitative findings are applicable at another context affirms transferability of findings (Polit \& Beck, 2012). The rich descriptions of the research process inclusive of the characteristics of the participants, analysis of qualitative data and scientific presentation of findings enhance transferability of findings (Thomas \& Magilvy, 2011).

\subsection{Ethical Consideration}

Prior to collection of data, permission was sought from relevant authorities namely; Human Science Ethics Committee, Faculty of Health sciences, the University of the Free State. The hospital management, the HIV positive pregnant mothers and their partners also granted permission. Informed consent signed after a briefing 
exercise and participation in the study was voluntary. Confidentiality upheld through attaching codes on each recorded tape instead of the participants' names. No other person who was not involved in the study had access to information, and the tape-recorded material was stored in a safe place until the study was completed. The following ethical principles were upheld.: Beneficence, justice and confidentiality.

\section{Results}

The four themes and sub-themes emerged after elaborate qualitative content analysis. The themes identified include; socio-cultural practices, time factor, information and educative strategies.

Table 1. Themes and sub-themes from the Basotho male participants

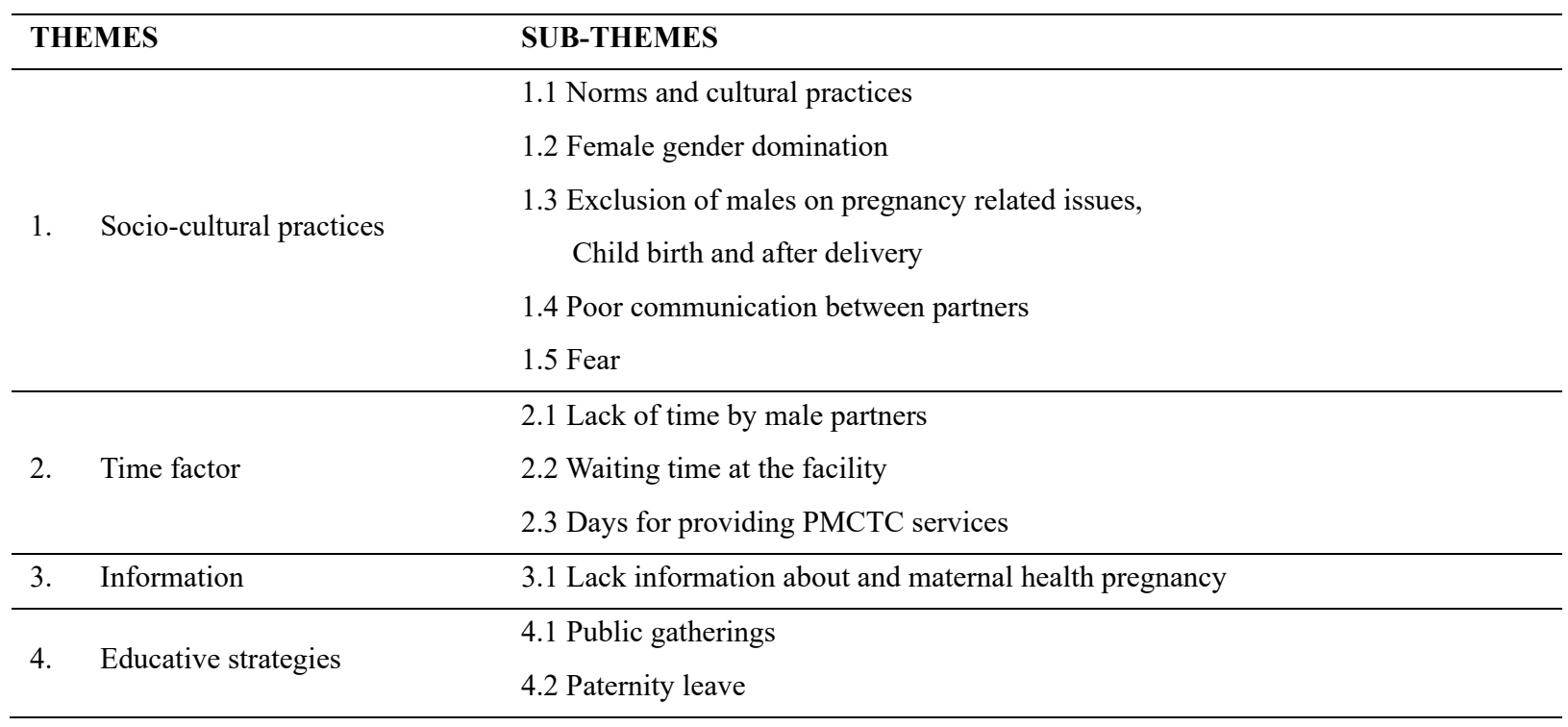

\subsection{Socio-Cultural Practices}

A number of factors associated with socio-cultural stereotypes frustrates meaningful participation of societies to curb the pandemic. In many African cultures, reproductive related issues within any family regarded as female related in nature (Elias, Mmbanga, Mohamed, \& Kishiba, 2017)

\subsubsection{Norms and Cultural Practices}

According to the Basotho culture, at about seven months of pregnancy, the young woman pregnant for the first time is send to her parent's home to deliver safely. The experienced mother educates the daughter about birthing postnatal care and breast feeding. This practice excludes the baby's father who remains at home (Kroeker \& Beckwith, 2011).

The participants highlighted the existing gender stereotypes within the Sesotho culture:

..... "As Basotho men, we are raised up in a manner influencing our thinking that certain responsibilities are meant for women." (Participant \#5)

\subsubsection{Female Gender Domination}

The ratio disparity between male and female nurses creates major communication problems with male clientele who are not free to discuss sexual problems in depth with female nursing personnel culturally regarded, as inferior to male peers and being quite young.

"In most clinics, women or young girls are main service providers. As a result, one does not feel free to reveal one's problems. I wish we could have many more men in these positions so that we as men, would feel a lot freer than we are right now." (Participant \#7)

\subsubsection{Exclusion of Males on Pregnancy Related Issues Birth and after Delivery}

Certain cultural practices exclude male participation in the PMCTC related issues. A paradigm shift on inherent cultural stereotypes within communities is urgent to fight the HIV/AIDS scourge (Elias et al., 2017).

Participants reflected dissatisfaction concerning this cultural practice separating them with their partners by 
indicating that:

"She will spend the remainder of pregnancy with elderly women (her mother) until the child is born. It must "be pointed once again that at this time, $i$ as the husband am away from her, therefore I know nothing since our culture exclude men from participating in reproductive related issues." (Participant \#7)

\subsubsection{Poor Communication}

Good communication on different reproductive issues is crucial in mitigating the HIV/AIDS pandemic. A meaningful approach encourages couples to communicate and negotiate safer sex and prevent STI'S and HIV/AIDS (The United Nations Population Fund, Technical paper No 3, on Partnering, A new approach to Sexual Reproductive Health, 2000).

One participant confirmed that, the lack of communication among couples is a key deterrent for male participation:

"The most common problem in many households in our community is that men and women do not communicate regularly about sexual matters which still regarded quite private and very embarrassing." (Participant \#5)

\subsubsection{Fear}

Different studies across Africa identified fear as a significant impediment towards meaningful participation in the PMCTC programs by men (Reece, Hollub, Nangani, \& Lane, 2010).

Some the participants strongly indicated that it is not easy for them as male partners to participate in PMTCT programs especially in attending antenatal care. They indicated for example, that:

"Fearing that people would think I am HIV positive when I accompany my wife to the clinic. These are some of the reasons making me scared attend or even seek any assistance at the clinic." (Participant \#4)

\subsection{Time Factor}

\subsubsection{Lack of Time by Male Partners}

Most Basotho males are not staying home due to work commitments (Lesotho Department of Statistics, 2009).

The following statements affirmed the participants' plight of lack of support to their partners due of work commitments and lengthy ques at the clinics:

"Being away from home due to work commitments actually makes us to have a tendency of shifting our responsibility.” (Participant \#5)

"Many of us we are away from home at mines, looking after animals or practicing farming, to mention but a few responsibilities we have to carry." (Participant \#1)

3.2.2 Waiting Time at the Facility

Increased waiting times in most health care facilities discourages men to participate in PMCTC programs. Countries such as Kenya have incentivized male participation by not allowing men who accompany their partner to que (Family Health international, 2009).

Participants affirmed that services are slow at the PMCTC

"We are quite reluctant to go to clinics because of slow

Service provision. The services take place during the course of the week." (Participant \#1)

"At work, one cannot even ask time off because

You wait too long in the line. This is usually not pleasing to

Our employers even if you explain the cause of delay." (Participant \#1)

\subsection{Information}

Some communities are still least informed on the benefits of supporting PMTCT HIV/AIDS prevention programs. Studies in other parts of Africa like Uganda affirm that men who have been introduced to PMCTC programs support their partners (Family Health international, 2009).

Participants affirmed their ignorance on the current reproductive related concerns and benefits of participation in PMTCT and prevention of HIV/AIDS programs.

"We as men lack the necessary knowledge regarding reproductive related issues including benefits of supporting our partners through PMCTC initiative. "(Participant \# 6) 


\subsection{Educative strategies}

More awareness educative campaigns initiated by the government and civil society empower men on diverse reproductive related issues (UNICEF, Strengthening through communication: A review of the literature, 2009).

\subsubsection{Public Gatherings}

Participants agreed in that public gatherings are good educative platforms for males on reproductive related issues:

"Well, most men in Lesotho may not open up to the idea of individually visiting clinics for such workshops, as a result I would recommend that you as medical practitioners go out to villages, particularly during public gatherings to offer such workshops." (Participant \#1)

"It is also important to involve local chiefs in this regard as men have a high regard of chiefs hence would attend in good numbers." (Participant \#2)

\subsubsection{Paternity Leave}

Gradually different constitutions are considering the significance of participation of a father in pregnancy, birthing and postnatal period. (News 24, Paternity leave in South Africa, 2014.

One participant echoed the need to give new fathers paternity leave for total support of the wife:

"Many companies do not support this practice Including societies. A man still has to plan the Clinic/delivery time around his annual leave." (Participant \#1)

\section{Discussion of Results}

The relatively, high HIV/AIDS statistics remains a concern where (23\%) of the population of Lesotho is infected with the virus. As a result, strong partnerships within families builds meaningful consensus seeing men fully participating in PMCTC related programs aimed at curbing the HIV/AIDS scourge within communities. Extensive literature concedes that successful participation of males on different reproductive health care programs especially in developing countries is still confronted with numerous challenges inclusive of; socio-cultural practices, gender stereotypes, exclusive reproductive services, services that are not time friendly to working males to mention but a few (Peacock \& Weston, 2008). In Lesotho, women infected with the HI virus are in the prime ages of 30 to 34. The socio-economic issues, culture and gender stereotypes compromise the bargaining power of women for safer sex (Lesotho Ministry of Health, National Guidelines: PMTCT, 2013).

The paper identifies the factors influencing the males in Lesotho from participating in PMCTC HIV/AIDS prevention program. The findings, reveal the following concerns as being key; socio-cultural practices, lack of time, ill-informed males on crucial services offered within the PMCTC HIV/AIDS prevention program like different screening tests done for mother, father and possibly on the new infant, family planning, and counselling fostering longstanding relationship with health care practitioners and the relevant family. Lastly, lack of sufficient information to males on reproductive related issues centered within PMCTC HIV/AIDS prevention program (Lesotho Ministry of Health, National Guidelines: PMTCT, 2013; Joubert-Wallis \& Fourie, 2008; Lesotho Ministry of Health National Health Strategic framework, 2018).

Extensive literature attests that the socio-cultural influences significantly influence envisaged participation by males on different reproductive initiatives involving their partners. Societal norms and cultural practices of Basotho influence their interpretation of illnesses and preventative approaches (Tjale \& Valliers, 2004). Like in many other African countries, Basotho cultural practices are still discriminatory to the males on reproductive related issues. The males do not fully support wives/partners during pregnancy, birth and postnatal due to inherent cultural stereotypes (Matsie, 2009). The exclusive practice to the males causes apathy and abdication of the domestic related family responsibilities. The constantly increasing pressure on the wife who even has extra workload of managing the extended family in the absence of a husband who possibly works away from home compromises participation of males in PMCTC related programs (Matsie, 2009). One participant agreed that socio-cultural and gender stereotypes influence the males from participating in the PMCTC program. "We are brought in the manner emphasizing that a child belongs to a woman not a man".

Availability of time by men who are bread winners poses as a serious obstacle for full integration of males in many PMCTC related programs in different countries. A significant proportion of Basotho men work locally or in the South African mining industry (Lesotho Department of Statistics, 2009). One participant raised the concern of not being home most of the time as a result of different responsibilities. "Many of us are away from home most of the time, in the mines, looking after animals or doing crop farming."

Furthermore, the long waiting time has been isolated as being key in discouraging male participation in PMCTC 
programs. Countries like Kenya are giving incentives to the males accompanying their partners to the antenatal clinic by not joining long ques (Family Health international, 2009). "We are quite reluctant to go to the clinic because of slow service provision and this becomes a time waster to someone with other responsibilities."

Services that are not client centered is one concern compromising PMCTC related services in many parts of the African continent (Family Health international, 2009). Men working away from home coming home over the weekend or sometimes end of the month, get frustrated by the time restrictive services opening only on week days. The participant echoed the issue of restricted time. "The services open only during the week when we are not home. Over the weekend, the clinics are closed."

Furthermore, poor participation by males is attributable to staffing issues affecting many health care systems in different parts of the world. The females who are mostly nurses constitute majority of the health care workforce contrary to other professions like medicine, which is predominantly male, gendered (Zelek \& Phillips, 2003). Statistically, male nurses are still grossly insignificant in numbers compared to their female colleagues (Tshibubu, 2006). This skewed gender representation is quite biased and friendlier to female clientele who are more comfortable to when examined by female nurses since the gynecological examination is quite invasive. In rural areas, male partners prefer consultation by male nurses at clinics contrary to the female nurses who are sometimes even younger. The males in Lesotho also do not feel comfortable when the male nurses consult their wives/partners (Tshibubu, 2006). One participant raised a concern of clinics predominantly managed by young female nurses. "In most clinics, women or young girls who have not even experienced birthing are the main service providers".

Different scholars from different disciplines propose a more inclusive strategy for educating males at different settings where they are readily available. For example, Kululanga, Sundby, Malata, and Chirwa (2011) propose educating males at different avenues such as; health facility, family, work places and community levels. Educative campaigns on the plight of HIV/AIDS and the role of men in protecting their family lineage through practicing safer sex becomes the responsibility of every Mosotho man. Such educative forums should constantly take place within communities at public gatherings, and through mass media platforms. In rural communities, the leaders/chiefs are quite instrumental in engaging different stakeholders such as community nurses and politicians at local constituencies to encourage participation of males. The participants endorsed the urgency of educating men on different reproductive related issues including HIV/AIDS. "I would recommend that health care practitioners go to the villages particularly during public gatherings and offer empowering talks."

Effective communication within families on an array of reproductive related issues is crucial in mitigating the HIV/AIDS pandemic. It is quite essential for men and women within healthy relationships to freely and deliberately join forces and choices to attain common sexual and reproductive goals. A meaningful approach encourages couples to communicate and negotiate for safer sex to prevent STI"s and HIV/AIDS through mutual respect, equality as well as ownership of decisions and their outcomes. One participant confirmed the existing lack of communication among couples. "The most common problem in many households in our community is that men and women do not communicate regularly about sexual matters still regarded as embarrassing”.

Another setback of fully integrating the males in the PMTCT HIV/AIDS preventative program is the stigma associated with HIV positive status (Towle \& Lende, 2008). Despite numerous advantages of knowledge of HIV status to partners, and their unborn child, communication of HIV status within Basotho couples is quite difficult, due to associated stigma (Towle \& Lende, 2008; Reece et al., 2010). The HIV/AIDS positive results on one partner usually create irreconcilable conflicts between couples. The fear of being associated with HIV positive results is a serious concern raised by participants. "I fear that people would think that I am HIV positive when I accompany my wife to the clinic."

The findings are quite insightful and reasonably address issues influencing desirable participation of males in PMCTCT programs. However, extensive literature takes cognizance bio-medical related issues to be significant influencers too. For instance, any existing STIs' and a very high HI viral load becomes an embarrassing deterrent to males especially (Lesotho Ministry of Health National Health Strategic framework, 2018). Delinquent Behavior seen in multiple sex partners and inconsistent condom use, alcohol and drug abuse also tend to scare voluntary participation in PMCTC HIV/AIDs prevention program. Social aspects attributable to; peer pressure, erosion of traditional values, sexual and gender-based violence are equally influential. Lastly, structural concerns such as; political, legal and environmental factors equally play key role in determining desirable participation by the males in Lesotho (Lesotho Ministry of Health National Health Strategic framework, 2018).

\section{Conclusion}

Basotho men already participate in a range of other reproductive related issues within families recognizing their 
leadership role. For instance, a Mosotho man participate in certain cultural practices welcoming the new baby and weaning of a baby. This becomes an excellent starting point, to build on programs that are more inclusive to males. Therefore, involvement of husbands at different stages of pregnancy birth and postnatal period affords males the opportunity to be educated on extensive issues on HIV/AIDS prevention, family planning, antenatal and nutrition. The concerns raised by participants about accessibility of some PMCTC HIV/AIDS prevention clinics are quite legitimate. Therefore, it is necessary to create more user-friendly facilities accommodating men with different responsibilities. It also sensible to support those men who accompany wives/partners to the clinic through creating an inviting experience for them. Communities need to step out of the socio-cultural stereotypical lenses based on gender through creating positive partnerships with males. The inclusive approach is quite relevant to Lesotho where the following concerns still exist; low condom use by males, greater burden of sexually transmitted infections, male dominance in sex-related negotiations, multiple sex-partners and misuse of alcohol.

\section{Recommendations}

Based on the findings of this study, the following recommendations proposed would improve realistic participation in PMCTC HIV/AIDS prevention programs by the males in Lesotho. Cognizance towards informing policy becomes critical through on-going research initiatives to influence desirable transformation of these programs:

\subsection{Legislative transformation}

Meaningful participation into PMCTC HIV/AIDS prevention programs requires a wider call from a wide societal spectrum to address different challenges influencing meaningful participation. More family centered laws promulgated to address the outstanding gender stereotypes and socio-cultural issues. For instance, consideration of laws promoting new paternity rights for fathers.

\subsection{Community Education}

Community mobilization through engaging different stakeholders like; government departments, non-governmental organizations like churches and chiefs. Mass media engagement aimed at empowering communities to reduce HIV/AIDS related stigma through radio, television, social media platforms and political rallies.

\subsection{Institutional Governance}

Constant engagement of leadership of concerned institution and being able to be pro-active in addressing concerns raised by public and research including staffing concerns. Male friendly PMCTC HIV/AIDS prevention services accommodating working males are essential.

\subsection{Capacity Development}

Capacity development to service providers to keep them abreast with changing treatment modalities aligned to global innovative research.

\section{Limitations of the Study}

- Extensive gate keeping technicalities making it difficult to gain access into the setting of the study posed as a challenge

- The home environment might have not have been ideal for discussion of HIV/AIDS related issues

- Freedom in discussing sensitive HIV/ AIDS related issues by the participants with female researcher could be limited due to possible gender stereotypes

- Quite difficult to establish a sizable sampling frame

\section{Competing interests Statement}

The authors declare that there are no competing or potential conflicts of interests.

\section{References}

Akarro, J., Deonisia, M., \& Sichona. F. (2011). An evaluation of male involvement on the program for PMTCT of HIV/AIDS: A Case Study of Ilala Municipality in Daares Salaam, Tanzania. Retrieved 20 January 2018 from http://astonjournals.com/assj

Akinsola, A., \& Mulaudzi, S. (2009). People's perception regarding HIV/AIDs prevention: A case study of rural community in South Africa. African Journal for Physical education, recreation and dance, 15(2), 204-222. https://doi.org/10.4314/ajpherd.v15i2.44654

Avert HIV/AIDS Lesotho. (2017). Global information and education on HIV/AIDS. Retrieved 15 September 2018 
from https://www.avert.org/professionals/hiv-around-world/sub- saharan-african/lesotho

Avert HIV/AIDS Lesotho. (2016). Global information and education on HIV/AIDS. Retrieved 16 September 2018 from https://www.avert.org/professionals/hiv-around-world/sub-saharan-african/Lesotho.

Avert prevention of mother-to child transmission (PMCTC) or HIV. (2018). Prevention of mother-mother-to-child transmission (PMCTC) of HIV. Retrieved 13 September, 2018, from https://www.avert.org/professionals/hiv-programming/prevention/prevetion- mother-child

Brink, H. I. (2006). Fundamentals of research methodology for health care Professionals. Cape Town: Juta \& Co

Burns, N., \& Grove, S. K. (2009). The practice of nursing research: Appraisal, Synthesis and generation of evidence (6th ed.). Saunders: Elsevier.

Creswell, J. W. (2009). Research design qualitative, quantitative and mixed methods approaches. Sage Publications: Los Angeles.

De Vos, A. D., Srydom, H., Fouche, C. B., \& Delport, C. S. L. (2005). Research roots (3rd ed.). Van Schaik.

Ehrhardt, A., Sawires, S., Mcgovern, J. D., Peacock, \& Weston, M. (2009). Gender, empowerment, and health: What is it? How does it work? Journal of Acquir Immune Defic Syndr. https://doi.org/10.1097/QAI.0b013e3181aafd54

Joubert-wallis, M., \& Fourie, E. (2008). Culture and spread of HIV. [Online] Available from: Department of Psychology 105. Retrieved 13 June, 2018, from 125www.hivimplemeters.com/oraIprent

Kharsany, A. B. M., \& Karim, Q. A. (2016). HIV Infection and AIDS in Sab-Saharan Africa: Status, Challenges and opportunities. Open AIDS Journal. Retrieved 13 June, 2018, from: http://www.ncbi.nlm.nih.gov/pmc/artcles/PMC4893541.

Kululanga, L., Sundby, \& Chirwa.E. (2011). Striving to promote male involvement in maternal health care in rural and urban settings in Malawi- qualitative study. Pubmed. https://doi.org/10.1186/1742-4755-8-36

Lesotho Ministry of Health \& Social Welfare. (2018). National HIV/AIDS Strategic Plan 2011/12-2017/18. Retrieved 3 September, 2019, from https;/hivhealthclearinghouse.unesco.org/sites/defalt/files/ resources/iiep-lesothodraftstrategicplan.pdf

Lesotho Ministry of Health \& Social Welfare. (2010). National guidelines for the prevention of mother to child transmission of HIV. Lesotho: Epic Printers. Retrieved 2 August, 2018, from $\mathrm{http} / / /$ www.unicef.org/aids/files/Lesotho-pmtctcfactsheet-2010pdf.

Lesotho Ministry of Health \& Social Welfare. (2013). National guidelines for the prevention of mother to child transmission of HIV. Lesotho: Xpress Graphics. Retrieved 5 August, 2018, from $<$ wwwemtct.iatt.org/wp-content.../03/Lesotho-pmtct-revised guidelines 2013 pdf.

Matsie, R. M. (2009). Gender relations and women's livehoods in the post-mine retrichments era: a case study at Mafeteng, Lesotho. Pretoria: UP. (Mini-Dissertation-MSc). Retrieved 5 August, 2018, from http://uphetd.up.ac.az/thesis/available/etd-09092010

Netshiswinzhe, M. D., \& Muladzi, F. M. (2015). Perceptions of nurse educators regarding the implementation of occupational specific dispensation at a selected nursing college in Limpopo. Health SA Gesondheid, 100-108. https://doi.org/10.1016/j.hsag.2015.04.003

Peacock, D., \& Weston, M. (2008). Men and care in the context of HIV and AIDS: Structure, political will and greater male involvement. Retrieved 5 September, 2019, from http://www.un.org/womenwatch/daw

Polit, D. F., \& Beck, C. T. (2012). Nursing research. Generating and assessing evidence for nursing practice (9th ed.). Philadelphia, United States of America. Lippincott and Wilkin.

Polit, D. F., \& Beck, C. T. (2012). Nursing research: generating and assessingevidence for nursing practice (9th ed.). Philadelphia: Wolters Kluwer Health/ Lippincott Williams \& Wilkins.

Reece, M., Hollub, A., Nangami, \& Lane, K. (2010). Assessing male spousal engagement with prevention of mother-to-child transmission programs in western Kenya. AIDS Care, 22(6) 743-750. https://doi.org/10.1080/09540120903431330

Rountree, M., Pomeroy, E., \& Marsiglia, F. (2008). Domestic violence shelters as prevention agents for HIV/AIDS? Health \& Social Work, 33(3), 221-228. https://doi.org/10.1093/hsw/33.3.221

South Africa Department of statistics. (2017). Mid-year population estimates. Retrieved 10 April from: 
www.statssa.gov.za

Thomas, E., \& Magilvy, J. K. (2011). Qualitative rigor or research validity in qualitative Research. Journal for Specialists in Pediatric Nursing, 16(2011), 151-155. https://doi.org/10.1111/j.1744-6155.2011.00283.x

Tjale, A. A., \& Valliers, L. D. E. (2004). Cultural issues in health and health Care (1st ed.). Cape Town.

Towle, M., \& Lende, D. H. (2008). Community approaches to preventing mother-to-child HIV transmission: perspectives from rural Lesotho. African Journal of AIDS Research 2008, 7(2), 219-228. https://doi.org/10.2989/AJAR.2008.7.2.7.524

Tshibumbu, D. (2006). Factors that influencing men's involvement in prevention of mother-to child transmission of HIV program in Mambwe district Zambia. University of South Africa: UNISA. (Mini-dissertation - MPH). Retrieved 29 November, 2017 from http://www.k4health.org/sites/default/files/male-involvement-pmtctpdf

UNAIDS. (2018). The Global HIV/AIDS Epidemic. Retrieved 15 May, 2018, from https://www.hiv.gov/hiv-basics/overview/data-and trends/global-statistics

UNICEF. (2009). Strengthening through communication: A Review of the literature. Retrieved 10 May, 2018, from https://www.unicef.org/southafrica/SAFresourcespmctccommunicationpdf

Zelek, B., \& Philip, S. (2003). Gender and power>: Nurses and doctors in Canada. https://doi.org/10.1186/1475-9276-2-1

\section{Copyrights}

Copyright for this article is retained by the author(s), with first publication rights granted to the journal.

This is an open-access article distributed under the terms and conditions of the Creative Commons Attribution license (http://creativecommons.org/licenses/by/4.0/). 